\title{
Productos biocidas
}

Según la definición del Ministerio de Agricultura, Alimentación y Medio Ambiente del Gobierno de España, (2016), los biocidas son sustancias activas preparadas, los cuales contienen una o más sustancias activas, o microorganismos cuya función es destruir, contrarrestar, neutralizar impedir la acción o ejercer un control sobre algún organismo dañino por medio de químicos o biológicos.

\section{Ilustración 1. Tipos de Biocidas}

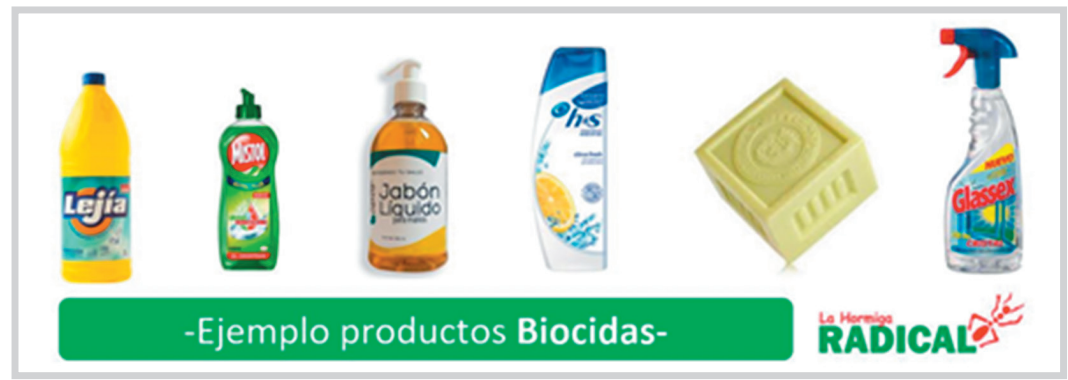

Fuente. https://bit.ly/2xdMeAk (La Hormiga Radical, 2016)

Existen 23 tipos diferentes de biocidas, los cuales se clasifican en 4 grandes grupos. Estos grupos son: desinfectantes y biocidas generales, conservantes, plaguicidas, otros.

\section{¿Por qué los empaques de los productos biocidas se} consideran residuos peligrosos?

Aunque el producto disuelto en agua no es tóxico, cuando se re-usan sus empaques sin haber sido lavados previamente puede ser contaminante para usos domésticos ya que podrían afectar la salud de personas y animales que tengan 
contacto con estos envases o que consuman líquidos o alimentos almacenados en ellos.

Igualmente, existe riesgo de incendio o explosión si el oxígeno liberado durante la descomposición térmica favorece la combustión, originado por el contacto con materias combustibles, productos inflamables o aumentos de temperatura en ambientes confinados.

\section{Manejo de envases plásticos con residuos de productos biocidas}

Para determinar si los empaques con residuos biocidas están siendo manejados de manera correcta o incorrecta, tenga en cuenta los siguientes aspectos:

\section{Manejo inadecuado}
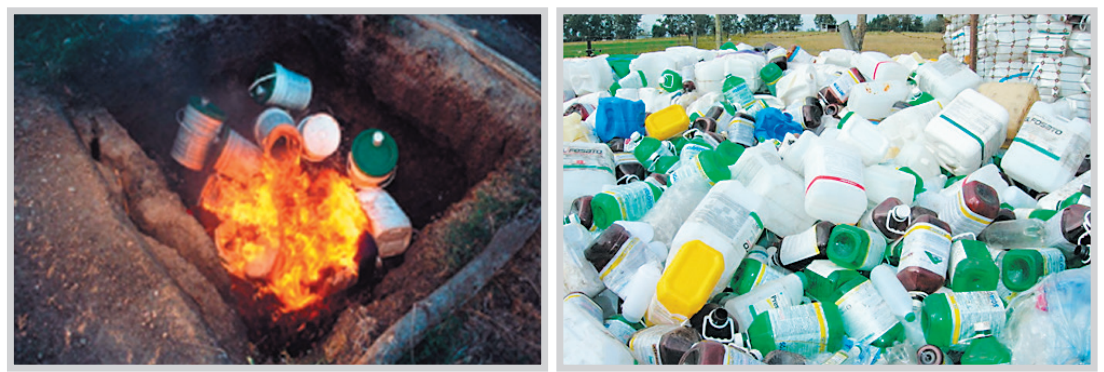

Fuente: https://bit.ly/20OePlJ (Diario Tag, 2017) y https://bit.ly/2Mac3qq (Masgoret, 2009)

»Cuando se almacenan los envases vacíos en un recinto con insuficiente ventilación.

»Cuando los envases se almacenan tapados

»Cuando quedan en contacto con productos inflamables o combustibles 
»Cuando se utiliza para recipiente de comida para personas o animales sin haber sido lavados previamente.

\section{Manejo correcto}

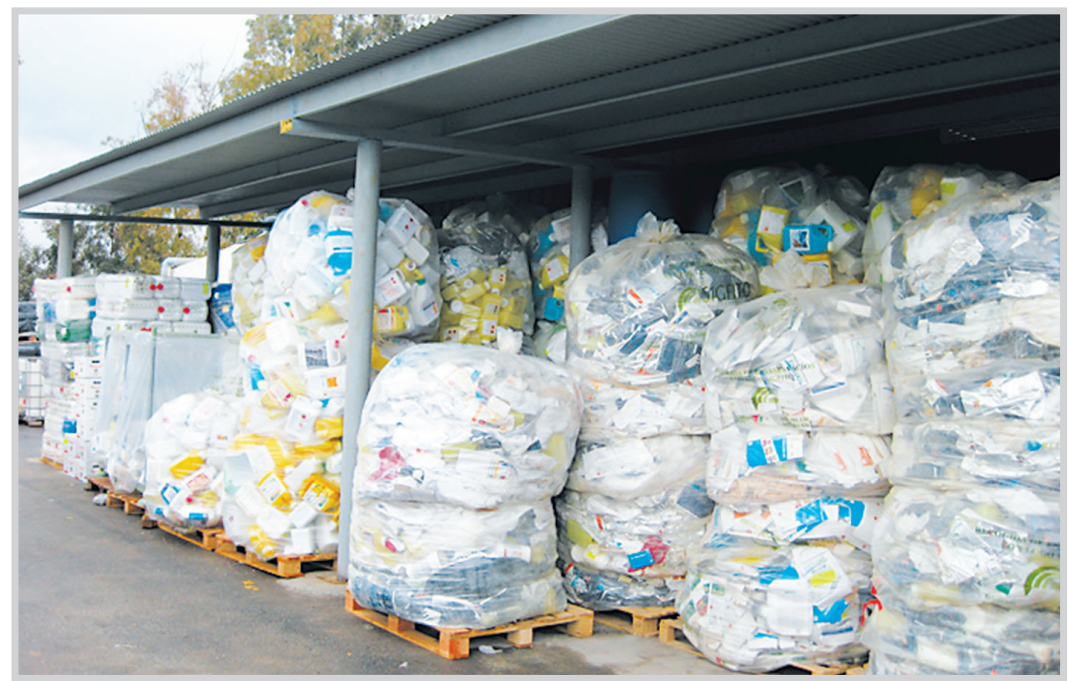

Fuente. https://bit.ly/2M2PwMp (Sigfito, 2018)

»Almacenar en área ventilada y alejada del calor.

» Utilizar mascarilla con filtro adecuado cuando se manipulan envases almacenados.

» No cerrar los recipientes herméticamente para evitar la acumulación de gases.

»No destinar los envases a usos diferentes a biocidas.

»Almacenarlos lejos de alimentos o utensilios de cocina.

» Utilizar equipo de protección durante la manipulación de los envases. 


\section{Responsabilidades}

Debido a las consecuencias que un mal uso de residuos biocidas puede ocasionar, las responsabilidades son, además de sancionatorias, de carácter ético por la implicación que se tiene sobre la vida y la salud de las personas y en el medio ambiente.

\section{Responsabilidad del productor}

»Informar a los clientes, trabajadores y comunidad en general acerca del adecuado manejo de los residuos plásticos de los biocidas.

»Hacer recolección de los residuos plásticos de biocidas para darles el destino final adecuado.

»Responsabilizarse por minimizar la producción de desechos plásticos de biocidas mediante la reutilización.

» Buscar alternativas adecuadas de disposición final de los residuos plásticos con biocidas que ya no puedan ser reutilizados (reciclaje o incineración)

» Proveer el equipo de protección al personal que manipula los envases desechados.

»Capacitar en el manejo de residuos peligrosos a los operarios encargados.

»Sensibilizar al personal de la empresa y clientes sobre el compromiso y protección del medio ambiente.

\section{Responsabilidad del consumidor}

»Seguir las instrucciones de las etiquetas sobre manejo de residuos peligrosos. 
»Devolver a la empresa los envases vacíos para ser reutilizados.

»Alertar cualquier anomalía en el envase del biocida.

» Darle un uso diferente al envase desechado, tales como envases para alimento y agua para personas o animales.

\section{Tratamientos}

Uno de los mecanismos más eficientes en el manejo de este tipo de residuos es la re-utilización, la cual genera menores costos, traducido en ventajas competitivas y en estrategias de responsabilidad ambiental, socialmente adecuadas.

Existen tres aspectos en los que se enfoca el tratamiento de residuos por envases plásticos contaminados:

» Recolección de envases contaminados: La empresa puede disponer de espacios adecuados para almacenar los recipientes vacíos contaminados después que el producto es utilizado, para posteriormente realizar los procesos de limpieza y re-uso.

»Almacenamiento temporal de envases: La bodega de almacenamiento debe tener la capacidad suficiente para almacenar los envases recolectados durante periodos determinados de tiempo necesarios para hacer la selección del material a reutilizar o reciclar. Durante este tiempo de almacenamiento, se deben tener en cuenta las recomendaciones dadas sobre el buen manejo del uso de envases plásticos con biocidas para evitar que los gases o vapores que se puedan formar, sean perjudiciales para los operarios que manipulen estos desechos. 
»Clasificación del material almacenado: Los operarios clasificarán los diferentes empaques de acuerdo a su estado. Se deben observar si están completos (con tapas funcionales), apartar los que tengan imperfecciones, estén rayados, tengan fisuras, etc. Se clasifican en dos grupos: material que Sí se puede reutilizar porque está en perfecto estado y material No reutilizable por encontrarse en mal estado, dañado, con fisuras, filtraciones o deteriorado.

\section{Tratamiento para materiales reutilizables}

»Triple lavado: Este procedimiento consiste en remover el producto que queda en las paredes de los tanques y garrafas llenando de agua estéril hasta un cuarto del volumen del envase, y agitarlo en todas direcciones, para finalmente disponer este enjuague para lavar pisos, ropa, riego de jardines, lavado de tanques, lavado de manos y cuerpo. Cuando se diluye este producto en bastante agua se convierte en desinfectante equivalente al hipoclorito, por lo cual su enjuague puede ser muy benéfico para la empresa. Esta acción se debe repetir tres veces, garantizando con esto que el 95\% de los químicos sean excluidos.

» Limpieza exterior: Hay que aplicar también una limpieza en el exterior de los recipientes con jabones y desinfectantes para poder renovar las etiquetas.

Por último, estos recipientes serán re envasados con el mismo producto biocida para ser nuevamente comercializados.

\section{Tratamiento para material No reutilizable - Disposición final}

»El reciclaje: Se envía el material de desecho a una empresa de reciclaje, donde lo pican y procesan para elaborar 
elementos de uso práctico para el campo como cajas selladas para el empaque y transporte de plaguicidas o para elaborar envases para productos que no sean de consumo humano o animal. Los envases plásticos rígidos se envían a plantas de reciclaje para hacer madera plástica.

» La incineración: La incineración es el tratamiento térmico se puede operar en hornos especialmente diseñados (verticales o giratorios). Los envases plásticos se envían a estos hornos cementeros que tienen licencia ambiental, los cuales manejan temperaturas cercanas a los 2.000 grados centígrados. Estos hornos tienen sistemas que permiten circular los humos, evitando emisiones contaminantes para el ambiente.

\section{Consejos útiles}

»Mantener el producto en un lugar seguro y protegido, ya que un manejo inadecuado puede generar fisuras en el envase provocando pérdida del producto y riesgos para la salud humana y para el medio ambiente.

" Se pueden dar usos alternos a los envases desocupados, tales como materas para sembrar plantas, almacenar herramientas de trabajo, convertir los envases en canecas para la basura, entre otros. Sin embargo, no se recomienda almacenar comida de personas o animales en ellos ya que pueden tener residuos contaminantes.

» Realizar actividades de recolección o reciclaje si en su región existen entidades creadas para tal fin. 


\section{Conclusiones}

Los biocidas son un producto muy útil que permite llevar una vida libre de gérmenes y microorganismos dañinos para la salud; sin embargo, se les debe dar un uso adecuado siguiendo las instrucciones que el fabricante indica en la etiqueta del envase. De esta manera se evitan errores que puedan causar afectaciones al medio ambiente.

Los envases vacíos que contenían biocidas se les considera residuos peligrosos (RESPEL) por el tipo de componentes químicos que conforman el producto, por lo tanto, éstos no se deben dejar al alcance de niños y animales. Así mismo, no se deben adaptar para servir alimentos ya que esto podría traer graves afectaciones a la salud de la persona o animal.

Por ningún motivo se deben abandonar los RESPEL en el campo, ya que podría contaminar el suelo y/o tener contacto con seres vivos. Por esta razón, siempre se deben lavar y almacenar para darles un nuevo uso o entregarlos a las entidades pertinentes. 



\section{Bibliografía}

Ariza Mejía, D. C., \& Henao Ríos, K. A. (2010). FORMULACIÓN DEL PLAN DE GESTIÓN PARA EL MANEJO DE RESIDUOS. Pereira.

B\&M News. (25 de mayo de 2018). B\&M News. Obtenido de B\&M News: https://bit.ly/2NMKSXE

Diario Tag. (18 de julio de 2017). Diario Tag. Obtenido de Diario Tag: https://bit.ly/20OePIJ

Economía Circular y Minería Urbana. (30 de noviembre de 2105). mineriaurbana.org. Obtenido de mineriaurbana.org: https://bit. ly/2NFF2OY

Econoticias. (04 de enero de 2010). ecoticias.com. Obtenido de ecoticias. com: https://bit.ly/2x69le7

Fraqmaq. (27 de septiembre de 2012). Fraqmaq. Obtenido de Fraqmaq: https://bit.ly/2Mx783k

GCR Staff. (09 de febrero de 2016). Global Construction Review. Obtenido de Global Construction Review: https://bit.ly/1V2Z5tC

IDEAM. (2014). IDEAM. Recuperado el 10 de 10 de 2016, de IDEAM: http:// www.ideam.gov.co/web/contaminacion-y-calidad-ambiental/ respel 
La Hormiga Radical. (19 de diciembre de 2016). La Hormiga Radical. Obtenido de La Hormiga Radical: https://bit.ly/2xdMeAk

Masgoret, A. (14 de noviembre de 2009). slideshare. Obtenido de slideshare: https://bit.ly/2Mac3qq

Mexican Business Web. (14 de septiembre de 2012). Mexican Business Web. Obtenido de Mexican Business Web: https://bit.ly/2Qvk2C3

Ministerio de Agricultura, Alimentación y Medio Ambiente. Gobierno de España. (- de - de 2016). Ministerio de Agricultura, Alimentación y Medio Ambiente. Recuperado el 11 de 10 de 2016, de Ministerio de Agricultura, Alimentación y Medio Ambiente: http://www. magrama.gob.es/es/calidad-y-evaluacion-ambiental/temas/ productos-quimicos/biocidas/

Ministerio de Ambiente, Vivienda y Desarrollo Territorial. (03 de 03 de 2018). Gestión Integral de Residuos o Desechos Peligrosos. Obtenido de http://www.minambiente.gov.co: http://www.minambiente.gov.co/images/AsuntosambientalesySectorialyUrbana/pdf/ sustancias_qu\%C3\%ADmicas_y_residuos_peligrosos/gestion_integral_respel_bases_conceptuales.pdf

Prevencionar. (2014). Prevencionar.com. Obtenido de Prevencionar. com: https://bit.ly/2Op31ba

Sigfito. (27 de febrero de 2018). Sigfito. Obtenido de Sigfito: https://bit. ly/2M2PwMp 


\section{Biografía de las Autoras}

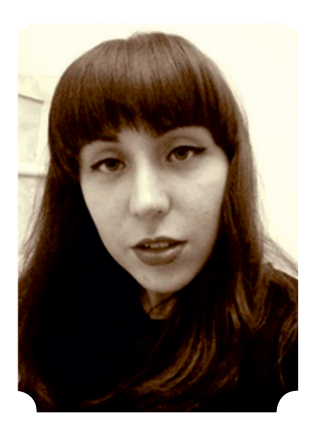

Laura Morales Rodríguez

Administradora de empresas de la Universidad Santo Tomás Seccional Tunja. Realizó la investigación tendiente a la elaboración de la tesis de grado denominada "Aspectos Relevantes de la Gestión Ambiental en una Empresa Importadora y Comercializadora de Productos Biocidas - Propuesta para el Manejo de Residuos Peligrosos por Envases Desechados" del cual se genera la presente cartilla como producto de investigación. Realizó práctica empresarial en la empresa OX CTA Colombia, donde se interesó en el manejo de residuos peligrosos, especialmente en el destino final de los envases plásticos con Biocidas. 


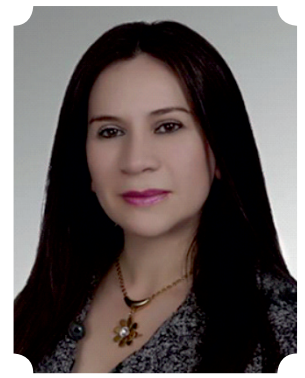

\section{Mg. Elvia Pilar Rodríguez Cely}

Docente Investigadora asociada a la Facultad de Contaduría Pública de la Universidad Santo Tomas Tunja - Directora de Investigaciones de la División de Ciencias Económicas Administrativas y Contables de Usta Tunja, Colombia. Contadora Pública Universidad de la Salle, Magister en Desarrollo sustentable y gestión Ambiental de la Universidad Distrital Francisco José de Caldas, especializada en Gerencia Estratégica de Costos y Control de Gestión de la Universidad Central de Colombia. Ha desarrollado investigaciones en temas referentes a instrumentos económicos ambientales y costos ambientales de los cuales se ha obtenidos premios y reconocimientos a nivel nacional e internacional.

\section{AGRADECIMIENTOS A:}

OX-CTA COLOMBIA

SAUL QUINTERO.

Médico veterinario y zootecnista 

Los residuos peligrosos originados por actividades industriales, es uno de los aspectos neurálgicos de las organizaciones actuales, debido a los impactos ambientales y sociales que un inadecuado manejo de los mismos puede generar. Sin embargo, es evidente que para la producción de bienes necesarios para el bienestar social se requiera realizar procesos de empaque o uso de productos que inevitablemente generan algún tipo de impacto negativo al entorno; es allí donde es imperante buscar alternativas de solución a la proliferación de estos residuos sin control y su disposición final.

La cartilla "Manejo de residuos peligrosos por envases plásticos desechados", presenta de manera didáctica y sencilla las pautas necesarias en el correcto manejo y disposición de envases plásticos que han sido utilizados para contener productos biocidas, situación que puede presentar riesgos a la salud humana y afectación ambiental si no se manejan de manera adecuada.

Este documento es el resultado de año y medio de trabajo investigativo de las autoras, quienes, en el marco del desarrollo de la tesis de grado, articularon las problemáticas reales de los usuarios, los riesgos y falencias en los mecanismos de disposición de residuos peligrosos con estrategias de control dispuestos en la normatividad ambiental. 